\title{
Rancang Bangun Mesin Pompa Air Otomatis Untuk Penyaluran Air Dari Tangki Ke Kran Pengambilan Air Di Desa Regaji Menggunakan Teknik Counter Berbasis Mikrokontroler
}

\author{
Leo Irvandi Tarigan, Saniman, Darjat Saripurna, Sri Murniyanti \\ Program Studi Sistem Komputer, STMIK Triguna Dharma \\ JI. A.H Nasution No.73 Medan, Sumatera Utara, 20142
}

\begin{abstract}
Abstrak
Warga desa Regaji dalam mendapatkan air untuk kebutuhan sehari-hari masih mendapatkan adanya kendala seperti telat dalam mendaptkan kebutuhan air untuk sehari-hari, karena proses penyaluran air masih dilakukan secara manual. Oleh, karena itu dibutuhkan suatu alat yang dapat menghemat waktu dalam penyaluran air di desa Regaji. Alat tersebut berupa sistem yang dapat bekerja otomatis untuk penyaluran air, dengan menggunakan alat ini diharapkan penyaluran air dapat dilakukan tepat waktu dan pada saat yang tepat. Penelitian ini dilakukan dengan membuat suatu perangkat sistem untuk penyaluran air otomatis menggunakan mikrokontroler ATMega16 sebagai pengendali utama dan sensor ultrasonik. Sistem ini juga menggunakan Real Time Clock (RTC) sebagai pewaktu dan Liquid Crystal Display (LCD) sebagai penampil. Mesin pompa air otomatis yang telah dibuat dapat menyalurkan air secara otomatis, apabila waktu sudah berada pada jadwal yang telah ditetapkan, maka proses penyaluran air akan dilakukan secara otomatis dan LCD akan menunjukkan waktu saat ini.
\end{abstract}

Kata kunci : Mesin pompa otomatis untuk penyaluran air Mikrokontroler, Sensor Ultrasonik, Real Time Clock (RTC), Liquid Crystal Display (LCD).

\begin{abstract}
Regaji villagers in getting water for daily needs still get obstacles such as late in disbursing water needs for daily, because the water distribution process is still done manually. Therefore, a tool is needed that can save time in water distribution in Regaji village. The device is a system that can work automatically for water distribution, using this tool is expected to be water dispensing can be done on time and at the right time. This research was conducted by creating a system device for automatic water dispensing using the ATMega16 microcontroller as the main controller and ultrasonic sensor. The system also uses Real Time Clock (RTC) as the timer and Liquid Crystal Display (LCD) as the viewer. The automatic water pump machine that has been made can channel water automatically, if the time is already on the set schedule, then the water distribution process will be done automatically and the LCD will show the current time.
\end{abstract}

Keywords : Automatic pumping machine for microcontroller water dispensing, Sensor Ultrasonik, Real Time Clock (RTC), Liquid Crystal Display (LCD).

\section{PENDAHULUAN}

Mesin Pompa Air adalah peralatan mekanis yang berfungsi untuk menaikkan cairan dari dataran rendah ke dataran tinggi. Pompa air digunakan untuk menyuplai air dari penampungan ke wadah yang akan diisi air [2]. Pada prinsipnya, pompa mengubah energi mekanik motor menjadi energi aliran fluida. Energi yang diterima oleh fluida akan digunakan untuk menaikkan tekanan dan mengatasi tahanan yang terdapat pada saluran yang dilalui [3]. 
Desa Regaji, Kecamatan Merek, Kabupaten Karo, Provinsi Sumatera Utara merupakan desa yang kebutuhan air sehari-hari warganya bergantung pada sumber daya air yang didapatkan dari air sumur bor, untuk mendapatkan air warga Desa Regaji menunggu pada pagi hari di jam 06:00 WIB saat mesin pompa air dihidupkan untuk penyaluran air dari tangki ke kran pengambilan air yang berada di dekat rumah warga dan jika jam sudah menunjukkan pukul 09:00 WIB, maka mesin pompa air akan dimatikan.

Proses penyaluran air masih dilakukan secara manual sehingga dalam pelaksanaanya masih ditemukan beberapa masalah, diantaranya yaitu, warga telat untuk mendapatkan air karena telat dalam menghidupkan mesin pompa air dan untuk menghidupkan dan mematikan mesin pompa air harus dilakukan berulang-ulang. Untuk mengatasi masalah di atas maka dibutuhkan suatu sistem yang dapat membantu warga dan pihak yang bertugas dalam menghidupkan dan mematikan mesin pompa air, sehingga warga tepat waktu dalam mendapatkan air untuk kebutuhan sehari-hari dan pihak yang bertugas dalam menghidupkan dan mematikan mesin pompa air tidak berulan-ulang dalam melakukan aktifitas tersebut.

Untuk mengatasi masalah di atas maka dibutuhkan suatu sistem yang dapat membantu warga dan pihak yang bertugas dalam menghidupkan dan mematikan mesin pompa air, salah satu cara yang dapat diterapkan adalah membuat mesin pompa air otomatis yang akan menyalurkan air tepat waktu dan terjadwal dengan menggunakan Teknik Counter, Real Time Clock, dan Mikrokontroler.

\section{METODE PENELITIAN}

Pada penelitian ini dibutuhkan adanya penyelesaian masalah dalam mengimplementasikan teknik counter pada sistem pompa air otomatis untuk penyaluran air dari tangki ke kran pengambilan air di Desa Regaji yang akan dibangun, sehingga akan membantu dalam menyalurkan air ke masyarakat di Desa Regaji.

1. Observasi / peninjauan langsung

Metode ini dilakukan dengan pengamatan secara langsung dilapangan tentang sistem yang dapat menyalurkan air ke kran pengambilan air. Kegiatan ini mengumpulkan beberapa hasil analisa yang akan dicantumkan pada tahapan algoritma sistem.

2. Study Literature

Metode ini dilakukan dengan cara mencari referensi melalui media seperti buku, dan jurnal, guna mengumpulkan data komponen yang dapat digunakan sebagai panduan atau pedoman dalam melakukan penelitian ini.

3. Eksperimen atau percobaan langsung

Metode ini merupakan pengumpulan data yang dilakukan melalui uji coba guna memperbaiki permasalahan yang terjadi, sehingga sistem yang akan dibangun dapat bekerja dengan baik. Setelah perangkat keras dan perangkat lunak selesai dibuat maka tahap berikutnya adalah pengujian sistem pompa air otomatis untuk penyaluran air dari tangki ke kran pengambilan air di Desa Regaji. Jika hasil tidak sesuai maka akan dilakukan perbaikan hingga sistem berjalan sesuai dengan yang diinginkan. 
Kerangka Kerja

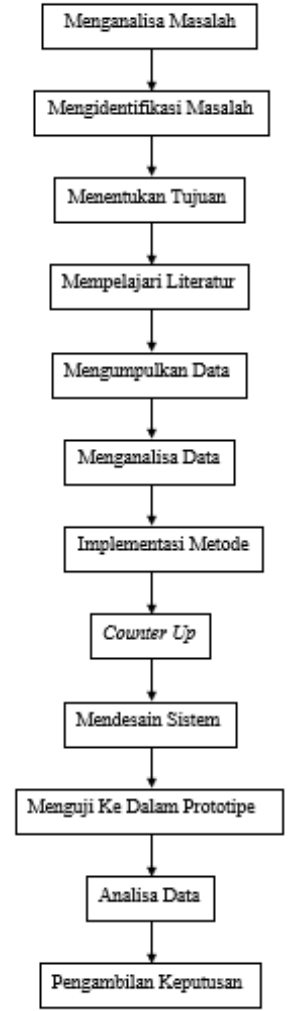

Tahapan Kerja Penelitian

1. Mengidentifikasi Masalah

Masalah yang diteliti dan akan dipecahkan dalam penelitian ini adalah bagaimana menyalurkan air dari tangka ke kran pengambilan air secara otomatis, untuk kemudian merancang sebuah prototype rancang bangun sistem serta pengambilan keputusan hasil proses.

2. Menganalisa Masalah

Analisa yang dilakukan dalam penelitian ini adalah dalam hal membangun sebuah sistem yang memanfaatkan metode counter dalam menyalurkan air secara otomatis.

\section{Menentukan Tujuan}

Menetukan tujuan penelitian dilakukan agar hasil yang diharapkan tidak berbeda dengan yang diinginkan adapun target yang akan dituju dalam penelitian ini adalah mengimplementasikan teknik counter dalam menyalurkan air dari tangki menuju kran pengambilan air di Desa Regaji.

4. Mempelajari Literatur

Mempelajari literatur-literatur yang berhubungan dengan penelitian ini yang dapat dijadikan referensi, dalam penelitian ini adapun literatur yang dipakai adalah jurnal-jurnal ilmilah, modul pembelajaran dan buku tentang Mikrokontroler, pengantar elektronika, aktuator dan robotika.

5. Mengumpulkan Data

Mengumpulkan data-data, khususnya data-data mengenai teori teknik counter, data-data pembuatan pompa otomatis, dan data-data tentang penelitian yang akan dibuat.

6. Menganalisa Data

Setelah data didapatkan kemudian dilakukan analisa data, dimulai dari mempelajari konsep dasar teknik counter, konsep pembuatan pompa otomatis, konsep Real Time Clock (RTC) dan konsep dasar robotika kemudian dilanjutkan dengan menganalisis kemampuan keseluruhannya.

\section{Implementasi Metode}

Melakukan implementasi teknik counter pada sistem sistem pompa air otomatis untuk penyaluran air dari tangki ke kran pengambilan air di Desa Regaji, sehingga sistem dapat dikedalikan dengan pengaturan waktu menggunakan RTC dan sistem dapat berjalan sesuai dengan yang diinginkan. 
8. Counter Up

Yaitu peroses perhitungan waktu maju pada Penyaluran air dari tangka ke kran pengambilan air dimana sebelumnya sudah ditetapkan terlebih dahulu.

9. Mendesain Sistem

Melakukan desain rancang bangun sistem dalam bentuk 3 dimensi. Penentuan komponen yang akan digunakan dan pemanfaatan Mikrokontroler untuk mengendalikan sistem.

10. Menguji ke dalam protoype

Setelah perancangan sistem rancang bangun, tahap selanjutnya yang dilakukan adalah tahap pengujian sistem berupa prototype. Hal ini dilakukan agar dapat melihat hasil kinerja sistem yang dibangun.

11. Analisa Hasil

Mengolah data hasil yang di dapat untuk kemudian dianalisa agar sesuai dengan hasil yang diharapkan.

12. Pengambilan Keputusan

Setelah keseluruhan hasil pengujian dan analisa diperoleh tahap akhir adalah pengambilan keputusan akan kelayakan sistem yang dirancang, sehingga dapat diimplementasikan ke dalam dunia nyata.

Algoritma Sistem

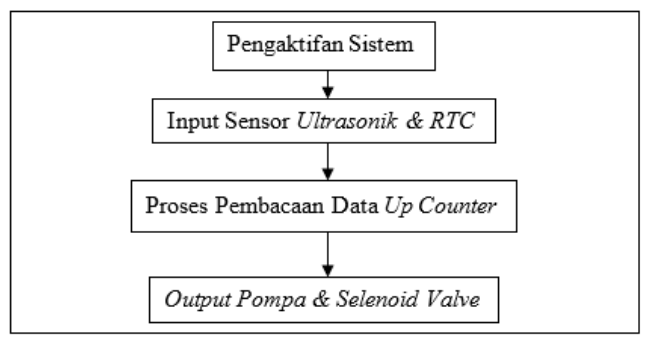

Algoritma Sistem

1. Proses pengaktifan sistem yaitu pertama kali sistem atau alat dijalankan pada saat catu daya dihubungkan.

2. Proses pendeteksian sensor ultrasonik untuk mengetahui jumlah air di dalam tangki, serta proses pengaktifan module RTC untuk menentukan penjadwalan waktu pengaliran air ke tempat pengambilan air.

3. Proses pembacaan data up counter, untuk melakukan penjadwalan waktu maju dalam proses pengaliran air ke tempat pengambilan air.

4. Proses pengaktifan pompa DC dan solenoid valve, pompa DC akan aktif jika sudah pada waktu yang telah dijadwalkan sebelumnya dan jumlah air di dalam tangki hampir kosong dan solenoid valve akan aktfi apabila waktu untuk pengambilan air telah sesuai dengan yang dijadwalkan.

\section{Counter Up}

Dalam sistem ini membutuhkan sebuah teknik counter yang berfungsi sebagai perhitungan dalam penjadwalan penyaluran air dari tangki ke kran pengambilan air di Desa Regaji yang biasa dilakukan pada pukul 06:00 WIB pagi sampai dengan pukul 09:00 WIB pagi setiap harinya. Sistem ini menggunakan Teknik counter up dalam pengoprasian penjadwalan penyaluran air. Dibawah ini merupakan tabel penjadwalan penyaluran air dari tangki ke kran pengambilan air di Desa Regaji.

\begin{tabular}{|c|c|c|c|c|c|}
\hline Jam & $:$ & Menit & $:$ & Detik & Keterangan \\
\hline 20 & $:$ & 00 & $:$ & 00 & Kran Selenoid Valve OFF \& Pompa ON \\
\hline 20 & $:$ & 10 & $:$ & 00 & $"$ \\
\hline 20 & $:$ & 30 & $:$ & 00 & $"$ \\
\hline 20 & $:$ & 59 & $:$ & 00 & $"$ \\
\hline 21 & $:$ & 00 & $:$ & 00 & $"$ \\
\hline 21 & $:$ & 10 & $:$ & 00 & $"$ \\
\hline 21 & $:$ & 30 & $:$ & 00 & \\
\hline
\end{tabular}




\begin{tabular}{|c|c|c|c|c|c|}
\hline 21 & $:$ & 59 & $:$ & 00 & " \\
\hline 22 & : & 00 & : & 00 & Kran Selenoid Valve OFF \& Pompa OFF \\
\hline 22 & : & 10 & : & 00 & \\
\hline 22 & : & 30 & : & 00 & $"$ \\
\hline 22 & : & 59 & : & 00 & " \\
\hline 23 & $:$ & 00 & $:$ & 00 & " \\
\hline 23 & $:$ & 10 & $:$ & 00 & " \\
\hline 23 & : & 30 & : & 00 & $"$ \\
\hline 23 & : & 59 & $:$ & 00 & " \\
\hline 00 & : & 00 & : & 00 & " \\
\hline 00 & : & 10 & : & 00 & $"$ \\
\hline 00 & $:$ & 30 & $:$ & 00 & $"$ \\
\hline 00 & : & 59 & $:$ & 00 & " \\
\hline 04 & $:$ & 59 & $:$ & 00 & $"$ \\
\hline 05 & : & 00 & : & 00 & " \\
\hline 05 & $:$ & 10 & $:$ & 00 & " \\
\hline 05 & : & 30 & : & 00 & $"$ \\
\hline 05 & : & 59 & : & 00 & " \\
\hline 06 & : & 00 & : & 00 & Kran Selenoid Valve dan Pompa ON \\
\hline 06 & $:$ & 10 & $:$ & 00 & " \\
\hline 06 & : & 30 & : & 00 & " \\
\hline 06 & $:$ & 59 & : & 00 & " \\
\hline 07 & : & 00 & : & 00 & $"$ \\
\hline 07 & : & 10 & $:$ & 00 & $"$ \\
\hline 07 & : & 30 & : & 00 & $"$ \\
\hline 07 & $:$ & 59 & $:$ & 00 & " \\
\hline 08 & : & 00 & $:$ & 00 & $"$ \\
\hline 08 & $:$ & 10 & $:$ & 00 & $"$ \\
\hline 08 & : & 30 & : & 00 & $"$ \\
\hline 08 & $:$ & 59 & & 00 & Kran Selenoid Valve dan Pompa OFF \\
\hline
\end{tabular}

2. ANALISA DAN HASIL

\subsection{Blok Diagram Sistem}

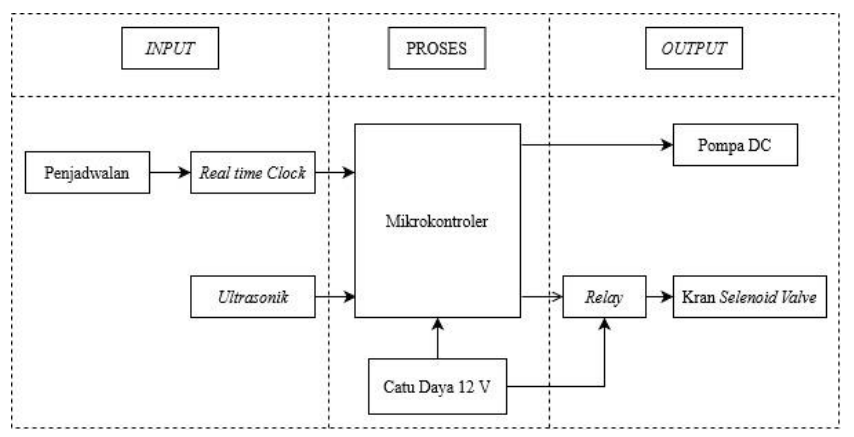

Blok Diagram

\subsection{Flowchart}

Flowchart ialah bagan alir yang menunjukkan alur kerja di dalam sebuah sistem secara keseluruhan dan menjelaskan urutan dari prosedur-prosedur yang ada di dalam sistem. Flowchart akan memberikan gambaran aliran data dari setiap input, proses dan output serta penjelasannya secara keseluruhan. 
Flowchart

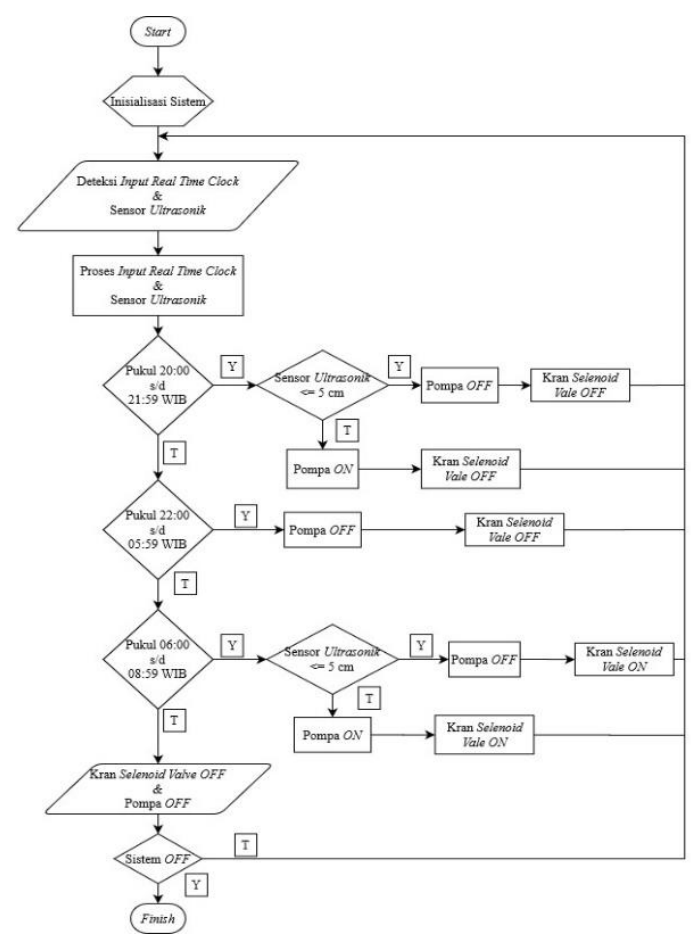

\section{Pengujian Keseluruhan Sistem}

Pada saat pengujian keseluruhan sistem pada pukul 20.00 WIB pompa akan on untuk mengisi air ke dalam tangki, jika waktu sudah menunjukkan pukul 22.00 WIB atau jarak antara air dan sensor ultrasonik $<=5 \mathrm{~cm}$, maka pompa akan off.
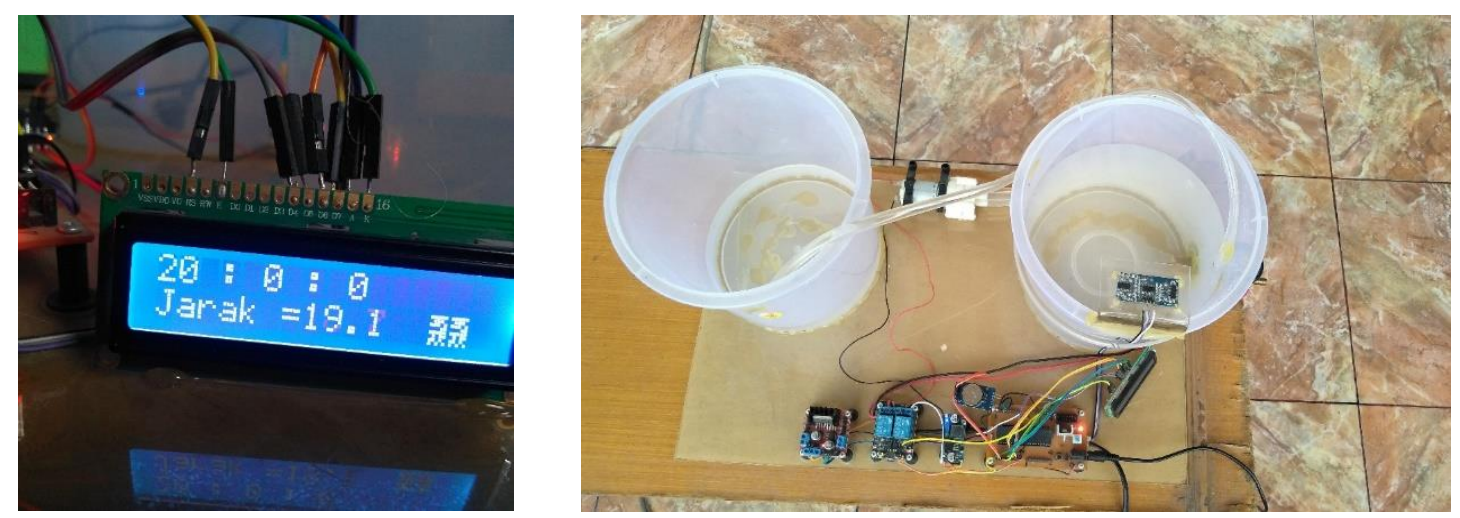

Pengujian Sistem Pukul 20.00 WIB

Pada pukul 06.00 WIB pompa akan on untuk mengisi air ke dalam tangki tapi, jika jarak antara sensor ultrasonik dan air $<=5 \mathrm{~cm}$, maka pompa akan off dan on kembali jika ketinggian air dan sensor ultrasonik lebih dari jarak yang telah ditentukan sebelumnya, sedangkan selenoid valve akan on pada pukul 06:00 s/d 09:00 WIB. 

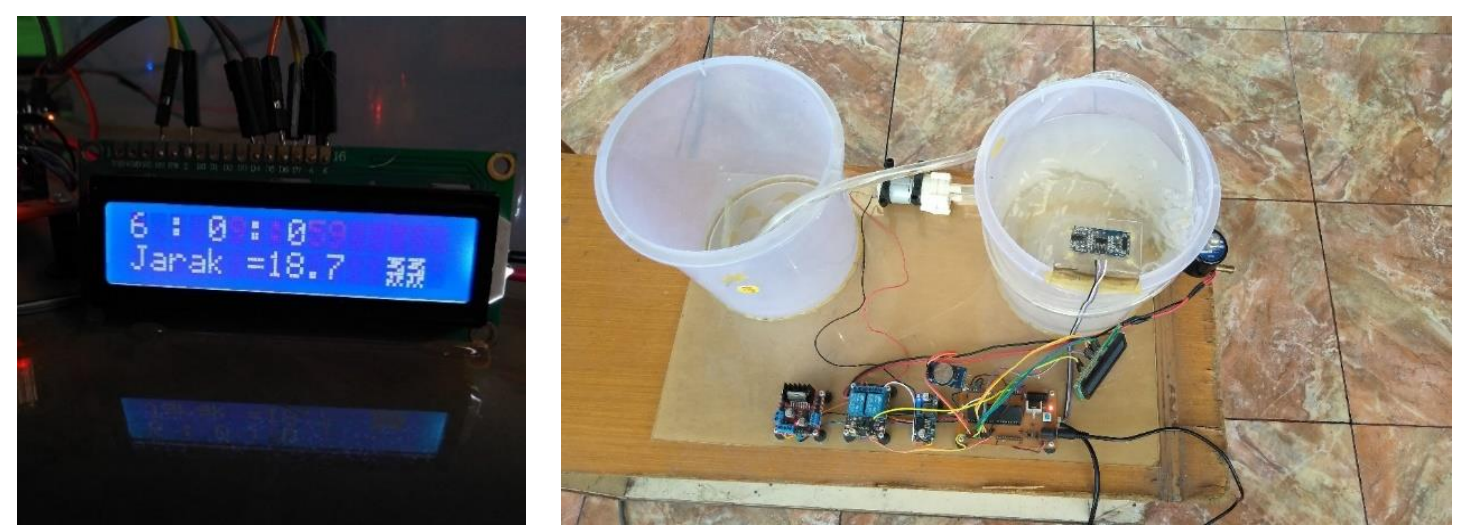

Pengujian Sistem Pukul 06.00 WIB

\subsection{Kelebihan dan Kelemahan Sistem}

1. Kelebihan Sistem

a. Sistem bekerja secara otomatis

b. Dapat memberikan pasokan air kepada warga secara tepat waktu

2. Kelemahan Sistem

a. Sistem tidak mempunyai cadangan daya, jika listrik mati sistem tidak dapat beroperasi.

b. Pada saat sistem dijalankan pada pukul 06:00 WIB terjadi error pada LCD.

c. Perancangan alat mesin pompa air otomatis untuk penyaluran air masih menggunakan komponen yang sederhana dan berupa prototype.

\section{KESIMPULAN}

Kesimpulan yang dapat diambil dari rangkaian dan sistem secara keseluruhan pada Rancang Bangun Mesin Pompa Air Otomatis Untuk Penyaluran Air Dari Tangki Ke Kran Pengambilan Air Di Desa Regaji Menggunakan Teknik Counter Berbasis Mikrokontroler adalah sebagai berikut:

1. Merancang mesin pompa air otomatis untuk penyaluran air dari tangki ke kran pengambilan air dapat dirancang dengan menggunakan pompa DC, kran selenoid valve dan real time clock, dimana pompa berfungsi untuk mengisi air ke dalam tangki dan kran selenoid valve berfungsi sebagai kran elektrik, sedangkan real time clock digunakan sebagai tempat penyimpanan waktu untuk melakukan penyaluran di waktu yang telah ditetapkan sebelumnya.

2. Menerapkan teknik counter pada rancang bangun mesin pompa air otomatis untuk penyaluran air dapat diterapkan dengan menentukan terlebih dahulu waktu sistem on dan waktu sistem off.

3. Implementasi/penerapan dari sistem yang telah dibuat dapat berjalan dengan baik untuk menyalurkan air dari tangki ke kran pengambilan air, pada pukul 20.00 WIB s/d 22.00 WIB pompa akan on untuk mengisi air ke dalam tangki sedangakan pada pukul 06:00 s/d 09:00 pompa dan selenoid valve akan on untuk

\section{REFERENSI}

[2] S. S. Kurniasih, D. Triyanto, Y. Brianorman, and J. S. Komputer, "Jurnal Coding, Sistem Komputer Untan Jurnal Coding , Sistem Komputer Untan ISSN : 2338493x," vol. 04, pp. 43-52, 2016.

[3] D. Program, S. Teknik, U. Dayanu, I. Baubau, S. Tenggara, and S. Valve, "PROTOTYPE PENGONTROL PENGISIAN TANDON AIR SECARA PARALEL MENGGUNAKAN SOLENOID VALVE BERBASIS ATMEGA 2560," vol. 7, no. 2, pp. 30-35, 2018. 